\title{
ARTÍCULOS
}

\section{EL COMODORO EDWARD CODRINGTON EN CATALUÑA DURANTE LA PENINSULAR WAR (1810-1813)}

\author{
Commodore Edward Codrington in Catalonia during the Peninsular War \\ (1810-1813)
}

\author{
Matías Ramisa Verdaguer \\ Doctor en Historia. Grupo de investigación PICEC (Univ. Autónoma Barcelona) \\ mramisa@yahoo.es \\ Orcid: 0000-0003-4803-3285
}

Recibido: 28-01-2020 Aceptado: 02-04-2020

Cómo citar este artículo/Citation:

Matías Ramisa Verdaguer, "El Comodoro Edward Codrington en Cataluña durante la Peninsular War (1810-1813)", Hispania Nova, 19 (2021): 1 a 34.

DOI: https://doi.org/10.20318/hn.2021.5874
Copyright: (c) HISPANIA NOVA es una revista debidamente registrada, con ISSN 1138-7319 y Depósito Legal M 9472-1998. Los textos publicados están -si no se indica lo contrario- bajo una licencia Reconocimiento-Sin obras derivadas 3.0 España de Creative Commons. Puede copiarlos, distribuirlos y comunicarlos públicamente siempre que cite su autor y la revista y la institución que los publica y no haga con ellos obras derivadas. La licencia completa se puede consultar en: http://creativecommons.org/licenses/by-nd/3.0/es/deed.es
Resumen: El capitán Edward Codrington prestó servicio entre 1810 y 1813 en las costas de Cataluña dirigiendo un escuadrón de la flota mediterránea de la Royal Navy. Ayudaba a los patriotas insurgentes contra la ocupación napoleónica. Aparte de la actividad bélica, Codrington se implicó mucho en la dinámica política del Principado impulsando un liberalismo radical. Quizá por motivos personales y en contradicción con su ideología, tomó partido contra el capitán general Luis Lacy y a favor del Barón de Eroles. Su idea principal era la de armar a todo el pueblo para luchar contra los franceses y hacer una revolución. El artículo también describe el marco general de la situación en el Mediterráneo y la personalidad de dicho capitán.

Palabras clave: Peninsular War, Guerra de la Independencia, Royal Navy, Cataluña, Luis Lacy, Edward Pellew.
Abstract: Captain Edward Codrington served between 1810 and 1813 off the coast of Catalonia, leading a squadron of the Royal Navy's Mediterranean fleet. He aided the patriotic insurgents against the Napoleonic occupation. Apart from the warlike activity, Codrington became very involved in the political dynamics of the Principality, promoting radical liberalism. Perhaps for personal reasons and in contradiction to his ideology, he took sides against Captain General Luis Lacy and in favor of Baron de Eroles. His main idea was to arm all the people to fight the French and make a revolution. The article also describes the general framework of the situation in the Mediterranean and the personality of said naval captain.

Keywords: Peninsular War, War of Independence, Royal Navy, Catalonia, Luis Lacy, Edward Pellew. 


\section{LA SITUACIÓN EN EL MEDITERRÁNEO AL INICIO DE LA PENINSULAR WAR}

Francia y Gran Bretaña habían firmado la paz de Amiens en marzo de 1802 y puesto fin así a una década de hostilidades. El tratado exigía que Inglaterra renunciara a la soberanía de Malta, pero el gabinete inglés no estuvo dispuesto a hacerlo y prefirió reanudar la guerra al año siguiente. De hecho, Malta se estaba convirtiendo en el centro del dispositivo británico en el Mediterráneo: base para navíos y convoyes, depósito del contrabando y almacén de los productos llegados de la zona oriental del mar. Su utilidad creció con el establecimiento del bloqueo continental a finales de $1806^{1}$.

Los británicos no habían olvidado la expedición napoleónica a Egipto. Sabían que el designio último del emperador francés -después del proyecto frustrado de invasión directa por el Canal- era la asfixia económica del Reino Unido y el ataque a sus colonias en la India a través del avance galo por el Mediterráneo oriental. Para evitarlo, el gobierno inglés expidió una poderosa flota a estas aguas y fortaleció sus bases marítimas en la zona.

A la altura de 1808, la flota británica en el Mediterráneo constaba de unos ochenta barcos de guerra, de los cuales casi un tercio eran grandes navíos de línea de más de 64 cañones; en el cénit del conflicto peninsular la armada llegó a más de cien embarcaciones, tripuladas por casi treinta mil marineros e infantes de marina ${ }^{2}$. El coste de semejante dispositivo fue colosal, pero también fueron enormes los beneficios comerciales y de hegemonía que permitió.

Si bien el volumen del comercio mediterráneo no era muy importante para Inglaterra, dado el nuevo contexto de guerra económica el Reino Unido debía luchar por las fuentes de materias primas, forzar la entrada de los productos británicos en cualquier

\footnotetext{
${ }^{1}$ Piers Mackesy, The War in the Mediterranean, 1803-1810 (London: Longmans, Green and Co., 1957), 8-12.

${ }^{2}$ NATIONAL MARITIME MUSEUM (NMM, Greenwich, Londres), PEL/8, informe de Pellew sin fecha (seguramente de finales de 1812). En este informe, el almirante Edward Pellew, comandante en jefe de la flota mediterránea, evalúa en 114 el número de barcos de guerra de la armada bajo su mando.
} 
mercado aunque fuera a través del contrabando, y tomar represalias para presionar al enemigo ${ }^{3}$.

La presencia de la Royal Navy en el Mediterráneo comportó también un beneficio político al permitir el contacto de Gran Bretaña con sus intermitentes aliados europeos -Austria y Rusia- y con el imperio turco, a pesar del estricto control continental que ejercía Napoleón.

Las bases de la flota mediterránea inglesa aumentaron durante esta etapa. Al principio eran únicamente Malta y Gibraltar, puerto éste último de gran importancia militar y económica. Con el tiempo se sumó la isla de Sicilia (1806) -donde la presencia inglesa fue más o menos consentida por los monarcas Fernando y María Carolina como protección contra los franceses que habían ocupado Nápoles-, y Mahón (1808).

Sicilia era el granero de Malta y tenía un territorio amplio y una posición estratégica en el centro del Mediterráneo ${ }^{4}$. Allí fue enviado un ejército de 30.000 hombres, dos tercios de los cuales eran empleados como guarnición frente al peligro francés. No fue hasta 1812 cuando parte de estas tropas pudieron ser enviadas a la costa levantina de España para que efectuaran una actuación en favor de Wellington.

Después de la sublevación española contra la invasión napoleónica, los ingleses negociaron con el capitán general de las Baleares Juan Miguel de Vives y obtuvieron permiso para que la flota pudiera usar el puerto de Mahón, aunque no pudieron desembarcar tropas. De este modo las Baleares quedaron de alguna manera bajo protección británica durante la guerra, y por ello la guarnición española de las islas pudo desplazarse a Cataluña ya en el mismo verano de $1808^{5}$.

El uso del puerto de Mahón fue utilísimo para la armada británica. Al ser su principal cometido la vigilancia de la escuadra francesa de Toulon, el grueso de la Navy podía permanecer en Menorca durante los inviernos, ya que la distancia a Toulon era mucho menor que desde Sicilia. Unos pocos navíos dejados como vigilancia en el golfo de León eran suficientes para dar la alerta en caso necesario.

\footnotetext{
${ }^{3}$ Piers Mackesy, The War in the Mediterranean, op. cit., pp. 8-12.

${ }^{4}$ Piers Mackesy, The War in the Mediterranean, op. cit., p. 15.

${ }^{5}$ NATIONAL ARCHIVES (NA, Kew, Londres), CO 173/2, cartas del almirante Collingwood a Vives y al contraalmirante Martin de 13 y 14 de julio de 1808. Las prioridades de Collingwood, comandante en jefe del Mediterráneo, eran en este momento aprovisionar de armas a los patriotas españoles, asegurar el puerto de Mahón y bloquear Barcelona. «The Interests of Spain and of England are identified, and their efforts should be united against the common Enemy», le dice a Vives.
} 
Mahón servía también como base de aprovisionamiento, como punto de etapa para los mercantes y como lugar de solaz de la marinería. La actividad era frenética en la amplia bahía. Otro punto frecuentado por la flota británica era el cabo de San Sebastián, algo al norte de Palamós; aquí, al resguardo de los fuertes vientos del golfo de León, eran interceptadas las embarcaciones francesas que pretendían aprovisionar Barcelona.

No hubo grandes batallas navales en el teatro mediterráneo durante la contienda. La probada superioridad inglesa -no en número de barcos, sino en destreza y materialbastó para mantener la flota francesa anclada en Toulon, sin ánimos para intentar romper el bloqueo británico. La lección de Trafalgar había sido definitiva.

Tan solo en una ocasión, a finales de octubre de 1809, la escuadra de Toulon organizó un convoy de cierta envergadura para aprovisionar Barcelona, que fue desbaratado y destruido por los británicos en las aguas limítrofes entre España y Francia $^{6}$. En general, la guerra que se libró en el Mediterráneo fue de pequeños encontronazos y persecuciones navales, de bloqueos y de corsarios, de bombardeo de los buques ingleses sobre las columnas francesas visibles en el litoral, de ataques a baterías costeras y desembarcos esporádicos. Pero el éxito del poder naval británico fue incontestable ${ }^{7}$. La presencia militar y comercial francesa y de los países satélites desapareció de los mares, incluido el Mediterráneo.

Después de Austerlitz (1805), el gabinete de Londres dirigido por Lord Grenville efectuó notables esfuerzos para llegar a una paz con Napoleón. Pero las conversaciones de 1806 fracasaron por la exigencia de Napoleón de obtener Sicilia. Con la administración Portland, los «halcones» regresaron al poder a partir de marzo de 1807, y viraron de nuevo a una política agresiva de contención del poder de Napoleón.

Esta fue de hecho la política que siguió Londres hasta el final del conflicto en 1815. Con la destrucción de la flota danesa en 1807 Gran Bretaña se había asegurado el predominio en el Báltico. Y el estallido antinapoleónico de la Península le permitió poner el pie en el continente para enfrentarse al emperador galo sin depender de otras

\footnotetext{
${ }^{6}$ Cuthbert Collingwood, The Private correspondence of Admiral Lord Collingwood (London: Edited by Edward Hughes, 1957), carta de 1.11.1809.

${ }^{7}$ Alfred Thayer Mahan, The Influence of Sea Power upon the French Revolution and Empire, 1793-1812, 2 vols. (London: Sampson Low, Marston, Searle and Rivington, 1892), vol. 2, 358 y ss.
} 
potencias europeas. A partir de entonces, la prioridad para el Reino Unido fue la ayuda a España y a Portugal ${ }^{8}$. Italia y Sicilia quedaron en un segundo plano.

\section{LA PERSONALIDAD DEL CAPITÁN EDWARD CODRINGTON}

Edward Codrington nació el 27 de abril de 1770 en el seno de una familia de la pequeña nobleza terrateniente - "baronets"- del Gloucestershire, que había tenido cierta importancia política desde el reinado de Eduardo III en el siglo XIV. Tanto su hermano mayor, Sir C. Bethell Codrington, como su sobrino, Christopher William Codrington, fueron miembros del parlamento ${ }^{9}$. Quedó huérfano muy joven y fue criado por un tío.

Enviado al internado londinense de Harrow durante un tiempo para su educación, a los trece años ya ingresó en la Royal Navy, y diez años después (1793) fue promovido a teniente. Eran los inicios de las guerras de la revolución francesa. Bajo la protección de Lord Howe, el joven Codrington sirvió en la flota del Canal y participó en la batalla del Glorious First of June de 1794. Fue ascendido a capitán en 1795 y durante dos años dirigió pequeñas fragatas de la Navy en el Canal y en la costa de Portugal, tomando parte en algunas acciones militares menores ${ }^{10}$.

A partir de 1797 quedó en tierra a media paga durante un largo período, hasta que zozobró la paz de Amiens en 1803. Un año antes se había casado con la inglesajamaicana Jane Hall, con la que tuvo tres hijos y tres hijas. Una vez reanudadas las hostilidades con Francia, el capitán Codrington fue adscrito a diversas fragatas. En 1805 obtuvo el mando del Orion de 74 cañones, un navío de línea con el que luchó en la batalla de Trafalgar ${ }^{11}$.

\footnotetext{
${ }^{8}$ Peter Hicks, «British strategic foreing policy, 1806-1815», Napoleon.org, The History website of the Fondation Napoleon (2016) https://www.napoleon.org/en/history-of-the-two-empires/articles/britishstrategic-foreign-policy-1806-1815/ (consultado el 29.08.2019), 1-6 y 8.

${ }^{9}$ John Saunders, Saunders' Portraits and Memoirs of Eminent Living Political Reformers ...: To which is Annexed a Copious Historical Sketch of the Progress of Parliamentary Reform . (J. Dowding, 1840), 151.

10 Marjie Bloy, «Sir Edward Codrington, (1770-1851)», A web of English History; http://www.historyhome.co.uk/people/cod-ton.htm (2016); Wikipedia, «Edward Codrington», Wikipedia The Free Encyclopedia, https://en.wikipedia.org/wiki/Edward Codrington (consultado el 31.08.2019).

${ }^{11}$ En la batalla de Trafalgar, Codrington, con el Orion, contribuyó a forzar la rendición de dos barcos de guerra franceses, el Swiftsure y el Intrépide.
} 
En la etapa siguiente Codrington fue integrado a la flota mediterránea del almirante Cuthbert Collingwood, y en noviembre de 1808 se le nombró para dirigir el Blake, también de 74 cañones. Con este navío participó en la desastrosa expedición de Walcheren de $1809^{12}$, y seguiría con él en los años siguientes, en los que el capitán se sumergiría de lleno en la Peninsular War.

En efecto, a principios del verano de 1810 Codrington fue enviado a Cádiz para cooperar con los españoles. Su primera misión fue el traslado desde esta ciudad a Menorca de cuatro destartalados barcos de línea españoles poco tripulados, mal aprovisionados y llenos de refugiados ${ }^{13}$, una travesía dificultosa que requirió 38 días. El convoy llegó a Mahón el 25 de septiembre.

Aquí descansó durante varios días y asistió a una cena con oficiales de marina españoles, donde la armonía fue la pauta, a pesar de la desconfianza mutua: «bebimos por la unión eterna de las dos naciones (...) aunque ellos continuaran sin apreciarnos mucho, y nosotros los despreciaremos por su fanatismo e inactividad» ${ }^{14}$. En su correspondencia de aquella época, Codrington revela abundantes detalles de su personalidad: era impresionable a primera vista y algo crédulo si un sujeto le caía bien, dado a hablar y escribir con franqueza y vehemencia, idealista y radical en lo político, y con una cierta conciencia de la superioridad inglesa. Gustaba de la lisonja y de la adulación, y estaba plenamente imbuido de su papel como portador de la libertad y de la independencia para España y -más adelante- para Cataluña.

Algunos de estos aspectos se revelan en su admiración sin límites por el general Enrique O'Donnell, entonces joven capitán general de Cataluña y recientemente victorioso en el combate de La Bisbal: «semejante esfuerzo y patriotismo lanzarán lejos

\footnotetext{
${ }^{12}$ Marjie Bloy, «Sir Edward Codrington, (1770-1851)», op.cit. (2016)

13 James Ralfe, The Naval Biography of Great Britain: Consisting of Historical Memoirs of Those Officers of the British Navy who Distinguished Themselves During the Reign of His Majesty George III, vol. III (Whitmore \& Fenn, 1828), 196 y ss.

${ }^{14}$ Lady Bourchier (ed.), Memoir of the life of Admiral Sir Edward Codrington: With selections from his public and private correspondence (London: Longmans, Green and Co., 1873), vol.1, 184-185. La principal fuente biográfica impresa sobre la vida de Edward Codrington la constituye este libro de correspondencia recopilado por su hija lady Janet Bourchier. Janet intenta mostrar una escrupulosa neutralidad a lo largo de los dos volúmenes de la obra; su pluma solo aparece en alguna nota o en algun comentario esporádico, y las alabanzas directas a su progenitor brillan por su ausencia. Pero, como no podía ser de otra manera, la selección de las cartas que reproduce destacan el aspecto humano y benefactor de Codrington; la gran mayoría fueron dirigidas por el marino a su mujer, y en ellas aparece a menudo la añoranza del capitán naval por su esposa e hijos, y por la plácida vida familiar que echa de menos desde la lejanía.
} 
de España el estigma con el cual la han marcado algunas de sus gentes más imbéciles». Enrique O'Donnell se había distinguido en el sitio de Gerona y por ello la Regencia lo había nombrado capitán general de Cataluña en enero de 1810 a propuesta de la Junta Superior de la provincia. Obtuvo algunos éxitos -victoria de La Bisbal, reorganización del ejército- pero también sonoros fracasos como las pérdidas de Lérida y de Tortosa. Al idilio inicial con la Junta del Principado y con la población le sucedió una relación tormentosa que llevó a Enrique O’Donnell a la dimisión a fines de 1810.

El 2 de octubre de 1810 Codrington dejó Mahón y se dirigió a Tarragona, donde fue a visitar a O'Donnell. Su fascinación creció. «O'Donnell ahora es absolutamente adorado por aquí, donde actúa con autoridad real», y añadía ${ }^{15}$ : «La frente del mismo Júpiter; y un ojo como el de Marte para amenazar y mandar (...); hará temblar al mismo Napoleón, creo (...). Y este héroe que tanto ha hecho tiene solo treinta y cuatro, y sus ayudantes de campo (...) son todos simples muchachos».

Los éxitos del ejército de Cataluña podían llegar a la reconquista de Barcelona, afirmaba Codrington. Y a pesar de ello, O'Donnell no podía obtener suministros, ni armas, ni instrucciones «de lo que se denomina el gobierno español». Y añadía Sir Edward: «E1 Principado siente ahora que está enteramente abandonado por el gobierno español, y se ve solo bajo la protección inglesa». El capitán viajaba con Charles William Doyle, agente militar inglés que se había labrado cierta reputación y del que Codrington decía que era «adorado» por la gente.

Doyle, como otros oficiales británicos que conocían el idioma español, fue enviado a la Península desde los primeros días de la sublevación antinapoleónica para servir de enlace con los patriotas ${ }^{16}$. Sirvió primero en Galicia y luego en la campaña por

\footnotetext{
${ }^{15}$ Lady Bourchier (ed.), Memoir, op. cit., vol.1, pp. 185-186. Enrique O'Donnell era valiente y activo, ambicioso y decidido; pero también muy impulsivo y poco previsor. Llegó a ser miembro de la Regencia de España en enero de 1812. El capitán Codrington mantuvo la idealización de este general durante toda su estancia en las costas levantinas españolas. Para tener mas referencias de la actuación de O'Donnell pueden consultarse Gómez de Arteche, 1868, vol. 8, pp. 221, 257-258, y Toreno, 1953, pp. 250 y ss.

${ }^{16}$ Lady Bourchier (ed.), Memoir, op. cit. vol.1, pág. 197. El coronel Doyle fue uno de los agentes militares ingleses más conocidos. De origen irlandés, era un hombre simpático, imaginativo, activo y entusiasta, que caía bien a los españoles que trataban con él. De todos modos, su actividad era algo dispersa. Como otros agentes, intentó al principio inmiscuirse en la política y dirigir los acontecimientos en España, por lo que tuvo que ser llamado al orden. A menudo sus informes exageraban los hechos o los revestían con cierta dosis de imaginación; a partir de 1812 se apartó de la primera línea. Véase J.W. Fortescue, A History of The British Army, 13 vols. (London: Macmillan and Co., Limited St. Martin's Street, 1910), vol.6, 257 y ss. También los historiadores clásicos de la Peninsular War, Napier y Oman, lo citan en sus ingentes trabajos. La hoja de servicios de Doyle en el ejército español se halla en A. Martin-
} 
Asturias y el País Vasco; marchó después a Madrid y posteriormente asesoró a Palafox en la defensa de Aragón. Finalmente recaló en Cataluña, donde en 1810 lo encontramos organizando la defensa de Tortosa, y en 1811 la de Tarragona.

Desde Tarragona, el capitán naval y Doyle continuaron a mediados de octubre de 1810 el viaje de inspección por el litoral valenciano. Codrington se emocionó por la confianza y la gratitud que la población mostraba hacia los ingleses. El día 21 ya se encontraban en la bella bahía de Alicante, una ciudad donde la gente ${ }^{17}$ «me parece que dicen lo que piensan abiertamente (...). Los edificios públicos son buenos, así como los trabajos, y las tiendas están ordenadas». Por la mañana tuvo a las hijas del cónsul en el barco para el desayuno «y estuvimos bailando (jincluso a mi edad!)».

En los meses siguientes, Codrington se desplazó con el Blake a Gibraltar y nuevamente a Mahón. El golpe de Campoverde en Cataluña de enero de 1811 le pareció bien al principio por el radicalismo revolucionario de este general, pero después empezó a desconfiar de su capacidad. A primeros de febrero de 1811 le hallamos patrullando la costa catalana y en marzo otra vez en las Baleares, donde se entrevistó con el convaleciente O'Donnell ${ }^{18}$. Por fin, en abril de 1811 se le encomendó a Codrington un escuadrón naval propio para operar en el litoral de Cataluña.

El carácter de Codrington era notable por varias particularidades. En primer lugar, parecía tener más vocación por la política que por la milicia. Él mismo confesaba que no quería ser un héroe como Nelson, no tenía suficientes aptitudes militares; y defendía el trabajo de los políticos, que podían llevar el bienestar y la felicidad a la gente mejor que los militares famosos, los cuales en ocasiones podían acarrear la miseria para un país.

"Realmente me pregunto (por) mi propia vacilación a este respecto, cuando reflexiono sobre mi falta de inclinación y la consiguiente incapacidad para la profesión de las armas (...). Y si bien los poderes más grandes de un Nelson o un Wellington solo pueden proyectar esto oblicuamente, un senador de igual valor e igual

\footnotetext{
Lanuza, Diccionario biográfico del generalato español. Reinados de Carlos IV y Fernando VII (17881833). (Legardeta,Navarra: FEHME, 2012), 269.

${ }^{17}$ Lady Bourchier (ed.), Memoir, op. cit. vol.1, pp. 187-192.

${ }^{18}$ Lady Bourchier (ed.), Memoir, op. cit., vol.1, pp. 203-204. El capitán naval aseguraba que O'Donnell hablaba «so openly» que un par de horas con él proporcionaban más información que toda una semana con otros; el general español se expresaba como si no tuviera nada que ocultar.
} 
eminencia, puede producirlo por sus propios esfuerzos individuales $y$ asegurar la bendición de la posteridad",19.

El amor de Sir Edward por la familia y la vida doméstica iba parejo a un ardiente interés por los asuntos públicos.

Mientras estuvo destacado en las costas de Cataluña con el escuadrón, su correspondencia se ocupaba más de aspectos políticos que de los hechos y las estrategias militares. En este último aspecto iba bastante por libre -el almirante le había dado carta blanca ${ }^{20}$ - y no se comprometía en grandes operaciones bélicas.

Cuando la situación era muy arriesgada, como en el sitio de Tarragona, actuaba con mucha precaución procurando primero salvar las vidas e intereses británicos. De vez en cuando cañoneaba las columnas francesas que pasaban a ras de costa, y participaba en operaciones militares coordinadas con el ejército español.

No se pueden negar a Sir Edward diversas cualidades que le atribuyen compañeros y partidarios. Poseía coraje -como demostró en los combates navales en los que participó- y diligencia, exhibió habilidades y una gran energía para conseguir sus propósitos. Aunque votó en contra de abolir la flagelación como castigo en la armada, se dice que era muy indulgente en temas disciplinarios y muy apreciado por los que servían bajo sus órdenes ${ }^{21}$.

En segundo lugar, y a pesar de venir de una familia aristocrática, Codrington tenía una ideología radicalmente liberal y en cierto sentido revolucionaria, a tono con la época del Romanticismo que se vivía. Exaltaba la libertad del pueblo y a veces escribía que éste -en Cataluña y en el conjunto de España- debería eliminar físicamente la clase alta, corrupta y tiránica. Veía una revolución violenta como la única solución para un país absolutista como España ${ }^{22}$.

Pensaba que los británicos debían impulsar la implantación de la libertad en España, tal como disponían las Cortes de Cádiz. La condición del pueblo, según él, era degradada por la esclavitud impuesta por el sistema, y sería necesario algún pequeño

\footnotetext{
${ }^{19}$ Periódico The Spectator, 29 noviembre 1873, pp. 17-18. Lady Bourchier (ed.), Memoir, op. cit., vol.1, pp. 192-193, 300-301.

${ }^{20}$ Lady Bourchier (ed.), Memoir, op. cit., vol.1, pp. 240-241.

${ }^{21}$ John Saunders, Saunders' Portraits, op. cit., pp. 150, 166.

22 John Saunders, Saunders' Portraits, op. cit., p. 165. Saunders le clasificaba dentro de la política británica entre los «moderate but decided reformers».
} 
«bloodshed» para forzar el cambio ${ }^{23}$ : «debido al grado de intolerancia y egoísmo que prevalece en los rangos superiores, la absoluta aniquilación de la mayor parte de ellos se ha convertido en un preludio necesario para la emancipación del pueblo».

Centrado su objetivo en redimir al pueblo, prefería la amistad de los jefes militares de origen popular o guerrillero, o al menos identificados con el territorio ${ }^{24}$. Por ello exaltaba a los guerrilleros Francisco Rovira y José Manso, y al principio también a Francisco Milans del Bosch. Pero sobre todo idolatraba al Barón de Eroles, a quien consideraba la quintaesencia de Cataluña.

En cambio, detestaba a los militares profesionales como Joaquín Blake y Luis Lacy; a este último llegó a profesarle una verdadera animadversión. Consideraba que para ganar la guerra había que armar a todo el pueblo y provocar un levantamiento en masa más o menos coordinado con el ejército regular, al que valoraba muy negativamente al igual que la mayoría de los militares británicos. Por contra, su exaltación de la guerrilla y de todo lo «popular» no era compartida por gran parte de sus compatriotas del ejército inglés, que en general apostaban por reforzar los mandos y las estructuras de la milicia convencional. No hay que confundir la ideologia liberal con el apoyo sistemático a la guerrilla en detrimento del ejército regular. El mismo Lacy era un ejemplo de militar liberal que abogaba por una tropa organizada y disciplinada. La revolución surgida del pueblo que Codrington quería aplicar a España era una idea personal, no necesariamente vinculada a su liberalismo. De hecho, su amigo el barón de Eroles no era liberal.

En tercer lugar poseía una personalidad pasional y emocionalmente inestable. Tenía altibajos, se volcaba hacia unos y despreciaba a otros según si le caían bien o no.

\footnotetext{
${ }^{23} \mathrm{NMM}, \mathrm{Cod} / 2 / 1$, cartas de 4.07.1811 y de 12.02.1812. Lady Bourchier (ed.), Memoir, op. cit., vol.1, pp. 200-201.

${ }^{24}$ El tema de la guerrilla generó controversia ya durante la guerra, y después entre los historiadores. Sectores populares y parte del partido liberal veían en ella la verdadera faz del patriotismo y de la lucha por la independencia, como una emanación directa del pueblo; al contrario, otros sectores dirigentes y los militares profesionales la rechazaban. La visión liberal ha predominado entre los historiadores. Hace un tiempo, Charles Esdaile y Antonio Moliner, entre otros, consideraron esta versión como un mito romántico y pusieron el acento en otros aspectos de los guerrilleros: vinculación de la guerrilla al ejército y al poder político, tendencia al bandolerismo y al pillaje, aventurerismo, crueldad, rechazo de la conscripción y de la disciplina, ambición e ineficacia militar. Moliner concluye que la guerrilla no fue tan decisiva para ganar la guerra. Véanse los libros de Ch. Esdaile, Fighting Napoleon. Guerrillas, Bandits and Adventurers in Spain 1808-1814 (New Haven \& London: Yale University Press, 2004); y de A. Moliner, La guerrilla en la Guerra de la Independencia (Madrid: Colección Adalid, Ministerio de Defensa, 2004).
} 
Con el tiempo a menudo cambiaba algunas de sus preferencias. En los informes que enviaba perfilaba una diferenciación diáfana entre buenos y malos en Cataluña. A menudo no había mucha objetividad en los reportes, lo que inducía a los superiores, probablemente, a tenerlos poco en cuenta ${ }^{25}$.

Era extrovertido, hablador y popular, pero a la vez un poco puntilloso y arrogante respecto de los catalanes y españoles en general, a los que no se cansaba de dar consejos y exigir un comportamiento determinado. Se confesaba optimista, y creía en el patriotismo de los catalanes y en la victoria final, a diferencia de muchos otros oficiales británicos. Pero al mismo tiempo a veces era poco prudente y poco diplomático en el trato con los demás, y propenso al cotilleo ${ }^{26}$.

Las cartas e informes de Edward Codrington están bien escritas. Cuidaba el estilo, usaba frases largas con subordinadas, se le nota cierto afán literario, a veces un punto de ironía. Como la mayoría de mandos de la época, pasó muchísimas horas escribiendo y dictando a sus tres secretarios.

\section{LA ACTUACIÓN DE CODRINGTON EN LAS COSTAS CATALANAS El sitio de Tarragona}

Como nuevo comodoro del escuadrón naval británico de Cataluña, Codrington asistió estupefacto a la novelesca toma del castillo de Figueras por parte del guerrillero Francisco Rovira el 10 de abril de 1811. Este revés obligó a los franceses a desalojar las pequeñas posiciones costeras y del interior que la fortaleza resguardaba, lo que permitió

\footnotetext{
${ }^{25} \mathrm{NMM}$, Cod/2/2, carta de Codrington de 2.12.1812; en ella se queja que no ha recibido respuesta a sus frecuentes peticiones de destitución de Lacy. De hecho, el embajador inglés Wellesley contestaba poco las cartas de Sir Edward, y cuando remitía informes al gobierno de Londres no solía citar al capitán naval de la estación de Cataluña sino al agente militar Edwin Green. Por otro lado, es posible que con el tiempo el carácter de Codrington se aquietara. Saunders atribuye a Codrington un temperamento calmado cuando era parlamentario, ya en la última etapa de la vida.

${ }^{26}$ Un ejemplo de ello es la carta que con fecha de 21 agosto 1812 le envió Codrington al Barón de Eroles, escrita en español: ««Hay voces que dicen que el edecan del Sr. Lacy que fue a bordo del Almirante Hallowell (...) ha hecho publicamente á la mesa de Lacy la observacion que el Capitan Codrington ha encontrado algunos chascos del General Inglés y del Almirante. Su nombre creo que es Chacon (...). De muy poca consideracion es la opinion que poede hacer este gran General L. (Lacy) y sus Chacons sobre mi conducta y mi caracter (...) Pero quiero mucho que los Catalanes no sean engañados para (por) la arte y la hypocrisia de estos señores, y sobre todos un tal Eroles (...). Mucho mas agradable esta de tener todo por bueno; pero estando la consideracion el interes de la Patria, no debemos admitir tales sueños deliciosos (...). Pero mi postrero aviso a la Cataluña sera, de no permitirse estar engañado por las buenas intenciones». NMM, Cod 2/1, carta de 21.08.1812.
} 
a las fragatas británicas destruir las fortificaciones y las baterías abandonadas del litoral, desembarcar en Cadaqués y hacer un amago sobre Rosas ${ }^{27}$.

Se reforzó el bloqueo naval de Barcelona, esencial para los ingleses. Pero pronto un acontecimiento de envergadura se sobrepuso a todo lo demás. El general Suchet comenzaba el sitio de Tarragona a primeros de mayo de 1811. El capitán Codrington vivió de cerca y participó en la defensa de la capital patriota de Cataluña con buena parte de su escuadrón naval.

Sir Edward consideraba Tarragona bien fortificada. Los buques de guerra y los botes armados británicos bombardeaban los destacamentos bonapartistas que se ponían a tiro a ambos lados de la urbe, transportaban las tropas españolas hacia los teatros de operaciones, y fueron a Valencia para reclamar refuerzos de soldados, artilleros y suministros. Aquí quedó muy bien impresionado por Carlos O'Donnell, hermano de Enrique, que había servido con Wellington y parecía el militar perfecto.

El comodoro constataba el patriotismo de los habitantes de Tarragona y veía la ciudad muy difícil de tomar. La causa de España es la de Inglaterra, escribía. Durante estos días de mayo ${ }^{28}$, Codrington todavía tuvo tiempo de explicar a su mujer los detalles de la toma del castillo de Figueras por parte del cura-guerrillero Francisco Rovira. «Entre otros efectos positivos de una revolución en un país esclavizado, está la de sacar de la oscuridad al tipo de hombres como el famoso Rovira, el héroe de San Fernando de Figueras». También le narró la historia del Empecinado. Mucha gente de la costa quería subir al barco de Codrington para verlo ${ }^{29}$, y a él le gustaba enseñarlo para contentar a las que él llamaba "poor creatures" o "poor catalans".

En la primera mitad de junio de 1811 el escuadrón de Codrington había abastecido Tarragona y había traído a la ciudad sitiada cuatro mil valencianos de apoyo comandados por el general Miranda. Pero el capitán desconfiaba de las intenciones de

\footnotetext{
${ }^{27}$ Lady Bourchier (ed.), Memoir, op. cit., vol.1, pp. 205-207.

${ }^{28}$ NMM, Cod/5/5, cartas de 8, 10 mayo 1811. Nick Lipscombe, Wellington's Eastern Front: The Campaign on the East Coast of Spain 1810-1814 (Pen and Sword Military, 2016), p. 186. Lady Bourchier (ed.), Memoir, op. cit., vol.1, pp. 209-212. El dia 10 de mayo la disposición del escuadrón de Codrington era la siguiente: el Blake, el Cambrian y el Termagant estaban en Tarragona; el Volontaire y el Undaunted se hallaban en el Cabo de Creus; el Guadaloupe estaba frente a Barcelona y el Sparrowhawk iba hacia Valencia. Lipscombe confirma que el escuadrón de Codrington tenía siete navíos de guerra en 1811.

${ }^{29}$ Lady Bourchier (ed.), Memoir, op. cit., vol.1, pp. 212-217. A pesar de su admiración por Rovira, a Codrington no le gustaba abrazar a este tipo de personajes españoles a causa del mal olor que desprendían, proveniente de una mezcla de ajos y tabaco.
} 
éste y sobre todo de la incompetencia del capitán general Campoverde, del cual criticaba «el infame abandono y la mala gestión». Sus temores se confirmaron el día 15, cuando Miranda se negó a reforzar la guarnición de Tarragona y se marchó para unirse al

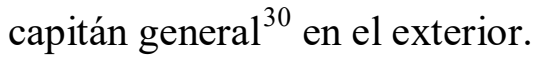

Pero el sitio de Tarragona se endureció y desde mediados de junio de 1811 se empezó a prever el final. A partir del día 21 los acontecimientos se precipitaron. El general Pedro Sarsfield huyó del puerto de la ciudad, acelerando la caída de este bastión a manos francesas. Juan Senen de Contreras, que mandaba la guarnición, criticó la salida de Sarsfield, a quien en cambio apoyaba Codrington ${ }^{31}$.

Por otra parte, el comodoro inglés interfería en las decisiones de Contreras; éste sustituyó en el mando al coronel de artillería Gerónimo Escales por Cayetano Laguisi, para complacerle. Codrington proporcionó algunos cañones para reforzar la defensa de las murallas. Campoverde, con un numeroso ejército de tropas bisoñas, seguía sin presentarse. Las fragatas británicas evacuaban a los heridos.

En estos momentos el ejército de Campoverde se hallaba en Torredembarra, pero no mostraba ninguna intención de acometer a los franceses ${ }^{32}$. «Campoverde irritado de la energía de mis oficios y del estado fatal de la Plaza pintado pateticamente escrive mil disparates que pudieran tener una fatal influencia en las tropas», le escribía el desesperado Contreras al comodoro inglés. Y añadía que aún se podía levantar el sitio ${ }^{33}$ «si repito atacan los nuestros con vigor por afuera».

Además del capitán general, otra muestra de falta de compromiso con los defensores de Tarragona la daba en estos días la fragata española Prueba, estacionada en la bahía. Ni se había incorporado a la defensa ni quería alojar a un grupo de heridos, que tuvieron que ser auxiliados por los ingleses, los cuales ya trasladaban hacia Vilanova i la Geltrú a otras dos mil personas ${ }^{34}$ entre heridos, mujeres y niños.

\footnotetext{
${ }^{30} \mathrm{NMM}, \mathrm{Cod} / 5 / 5$, informe al almirante Cotton de junio 1811 sin fecha concreta. Lady Bourchier (ed.), Memoir, op. cit., vol.1, pp. 218-220.

${ }^{31} \mathrm{NMM}, \mathrm{Cod} / 5 / 5$, informe de 22.06.1811.

${ }^{32}$ NMM, Cod/5/5, mensajes de Contreras a Codrington de 23.06.1811.

${ }^{33} \mathrm{NMM}, \mathrm{Cod} / 5 / 5$, mensaje de Contreras a Codrington de 24.06.1811.

${ }^{34} \mathrm{NMM}$, Cod/5/5, carta del general Doyle y mensajes de Contreras a Codrington de 27.06.1811. El capitán del Prueba era Pedro Barcaystegui.
} 
En la cadena de deficiencias que contribuyeron a la caída de Tarragona cabe incluir también a los británicos. El día 26 de junio se había presentado en la bahía un refuerzo inglés de 1.200 hombres a las órdenes del coronel John Skerret, pertenecientes a la unidad del general Thomas Graham. Codrington y Doyle decidieron que no entraran a reforzar la guarnición. El argumento fue que la ciudad estaba a punto de caer, y no se podía garantizar la seguridad de los llegados.

La guarnición de Tarragona deseaba vivamente que se les reunieran los hombres de Skerret, y Contreras había ofrecido a éste el punto de defensa que fuera más de su gusto. Pero en las instrucciones a Skerret el general Graham había escrito que no pusiera a sus hombres en la situación de ser apresados o tener que capitular ${ }^{35}$.

En su correspondencia, Sir Edward justificó largamente esta decisión, que intuyó era poco acorde con sus propias proclamaciones patrióticas y con las exigencias que hacía a otros en casos similares. La iniciativa de Graham había llegado demasiado tarde, no se necesitaban más artilleros, toda la división inglesa resultaría sacrificada, el fuerte oleaje impedía el desembarco, repetía Codrington ${ }^{36}$.

Pero la marcha del contingente de Skerret había desmoralizado a la guarnición. La ciudad había caído dos días después a manos de los soldados franceses, que provocaron una gran matanza. El ejército inglés dió una mala impresión. A causa de ello, los dos principales historiadores británicos que se han ocupado de la Peninsular War censuran la retirada del contingente. Napier reflexiona que mil marines de la flota podían haberse unido a las tropas de Skerret para hacer imposible el asalto de Suchet. Oman adjudica la culpa a Graham por sus instrucciones al coronel. El reciente y muy documentado libro de Antonio Moliner sobre el sitio de Tarragona también deja clara la responsabilidad británica en la caída final de la plaza; los ingleses tenían objetivos e

\footnotetext{
${ }^{35}$ Lady Bourchier (ed.), Memoir, op. cit., vol.1, pp. 224-226. El general Thomas Graham fue un importante militar británico de la Guerra de la Independencia española. Había participado en las luchas contra la Revolución Francesa, y acompañó a Sir John Moore en la dramática retirada hacia La Coruña de finales de 1808. Asignado a la defensa de Cádiz, ganó la batalla de Chiclana a los franceses en marzo de 1811. Después acompañó a Wellington como segundo al mando en las victoriosas campañas por el norte peninsular a partir de 1812 .

${ }^{36} \mathrm{NMM}$, Cod/2/1, carta a Graham de 29.06.1811; Cod/5/5, informes de 29.06.1811 al almirante Charles Cotton y a Henry Wellesley.
} 
intereses diferentes ${ }^{37}$. Les era suficiente con mantener su supremacía naval, y procuraban escapar de los combates en que podían ser destruidos.

En los días posteriores, Sir Edward explicó las brutalidades cometidas por los franceses en Tarragona, y su escuadrón colaboró en la evacuación de la gente que había escapado del desastre, así como en el retorno posterior de las tropas valencianas. En cambio, se negó a evacuar la infantería catalana y polemizó directamente con Campoverde. En la tarde del asalto, los barcos ingleses solo consiguieron salvar a unos seiscientos de los miles de fugitivos, que se rendían ante pequeños pelotones enemigos ${ }^{38}$. Mientras transportaba refugiados, la banda tocaba una danza española. No perdió el optimismo: de las cenizas de Tarragona resurgiría el patriotismo.

Las fragatas españolas Diana, Prueba y Astrea, habían hecho un triste papel en Tarragona. En cambio, la corbeta Paloma se había comportado muy dignamente. A ojos de Sir Edward y a los de mucha gente, Campoverde y Sarsfield se habían desacreditado. Al reflexionar sobre las causas del desastre, Codrington señaló que la principal había sido la ineptitud, la imbecilidad y quizás la traición de los principales dirigentes militares, especialmente de los dos citados. En cambio, consideró que él mismo había tenido un papel importante en la defensa de la ciudad ${ }^{39}$, y no hizo ninguna autocrítica.

\footnotetext{
${ }^{37}$ Sir William Francis Patrick Napier, History of the war in the Peninsula (New York: Ams Press, Inc., 1970, reprinted from the edition of 1862), vol. 3, 257. Sir Charles William Chadwick Oman, A History of the Peninsular War (Oxford: Clarendo, 1902-1914), vol 4, 521. Nick Lipscombe, Wellington's Eastern Front, op. cit., p. 28. Lipscombe considera que habría sido mejor que Skerret nunca se hubiera presentado: su venida era de poca ayuda, pero su retirada causó mucha desmoralización. Antonio Moliner Prada, Tarragona (mayo-junio 1811): una ciudad sitiada durante la Guerra del Francés (Madrid: CSIC, Doce Calles, 2011), 270-271. Para conocer detalles concretos del asedio de Tarragona desde el punto de vista inglés puede ser útil el libro muy reciente de Adam G. Quigley, redactado con documentación de los archivos del Reino Unido. En cambio, en el sobrio relato que el mariscal Suchet hace del sitio de Tarragona en sus memorias, apenas remarca el papel de la flota británica en la protección de la urbe. La principal preocupación de los atacantes, que él dirigía, era la vigorosa e implacable defensa de la plaza que realizaba la guarnición española, la cual les causaba muchas bajas. Valora especialmente al general Sarsfield, enérgico y eficaz. Evalúa -quizás exageradamente- el escuadrón británico presente en las aguas de Tarragona en dos navíos de línea, ocho fragatas y "bricks", y 30 naves de transporte. Apenas menciona un momento los refuerzos de tropas inglesas que intentó aportar el coronel Skerret. Véase Louis-Gabriel Suchet, duc d'Albufera, Mémoires du Maréchal Suchet, Duc d'Albufera, sur ses campagnes en Espagne (Paris: Adolphe Bossange; Bossange Père; Firmin Didot, 1828), vol. 2, 65 y ss.
}

38 NMM, Cod/5/5, informes de Codrington de 29.06.1811; Pel/13, carta de Campoverde de 7.07.1811.Lady Bourchier (ed.), Memoir, op. cit., vol.1, pp. 230-237. Codrington demuestra mucha sensibilidad con los fugitivos y refugiados en su correspondencia, especialmente con mujeres y niños. Declaró que había vestido y alimentado a muchos, gastando incluso mil libras de su propio peculio.

${ }^{39}$ NMM, Cod 2/1, carta de 4.07.1811; Cod/5/5, informe a Cotton de 29.06.1811; Cod/5/3, carta del almirante Cotton de 9.07.1811. Lady Bourchier (ed.), Memoir, op. cit., vol.1, pág. 235. 
En estos días trágicos Codrington descubrió al hombre que podría salvar Cataluña: el barón de Eroles. Éste asistió a la caída de Tarragona a bordo del Blake, y Codrington se convenció de que «sólo en el barón podría confiar el Principado sus esperanzas futuras» ${ }^{40}$.

\section{Tiempos de armonía (1811)}

A partir de la caída de Tarragona, el comodoro se sumergió de lleno en la vida política del Principado y en las intrigas entre los gobernantes. Recibió con expectación y alivio al nuevo capitán general español Luis Lacy y, aunque hubiera preferido al barón de Eroles, le dio su apoyo ${ }^{41}$. Según Sir Edward, Cataluña sólo podría recuperarse si los ingleses enviaban una fuerza militar considerable, o se aplicaba un decidido sistema revolucionario en la provincia. Insistió a la Junta Superior de Cataluña que se debería armar a todo el pueblo, y que él mismo distribuiría las armas. En este momento, en julio de 1811, algunos vocales radicales de la Junta (Pagès, Batlle, Segura) decían lo mismo.

Codrington se encontró el 29 de julio en Arenys de Mar con vocales de la Junta Superior, seguramente Esteban Pagès y José Batlle, y los halló dispuestos a perseverar en la defensa del país. Explicó al almirante su opinión sobre las desgracias de este pueblo bravo y perseguido, «perseguido no menos por la bajeza de su propio gobierno que por las sangrientas atrocidades de los franceses». Afirmaba que el ardor del pueblo era tan grande que nunca sería conquistado. Y añadía que lo que había que hacer era dar armas a todos los que quisieran usarlas para establecer la libertad del país, «aunque su modo de hacer la guerra pudiera no ser lo más agradable para la táctica y la regulación militar» ${ }^{42}$.

\footnotetext{
${ }^{40} \mathrm{NMM}$, Cod 2/1, informes de 29 junio y 1 julio 1811; Cod/5/5, informe de Codrington a Wellesley.

${ }^{41}$ NMM, Cod 2/1, carta de 1.07.1811; Pel/13, carta de 12.07.1811. Luis de Lacy Gautier (1772-1817) era hijo de militar español de origen irlandés y de madre francesa. A los trece años ingresó en el ejército español y en 1794 sirvió ya como capitán en la guerra contra la república francesa. En 1802 fue arrestado por una cuestión amorosa y en 1803 pasó al servicio de Francia. En 1808 desertó al negarse a colaborar en la invasión de España y reingresó en el ejército español, en el que alzanzó el grado de mariscal de campo en 1810. Al año siguiente fue nombrado capitán general de Cataluña y en enero de 1813 capitán general de Galicia. De ideología liberal, después del retorno del absolutismo conspiró contra Fernando VII y fue ejecutado en el castillo de Bellver, Mallorca, en 1817. La hoja de servicios de Lacy en el ejército español se halla en A. Martin-Lanuza, Diccionario biográfico, op. cit., pp. 466-467.

${ }^{42}$ NMM, Pel/13, informe al almirante de 29.07.1811; Pel/11, cartas de la Junta catalana pidiendo armas y asegurando que se mantiene el espíritu patriótico, de 31 julio y 5 agosto 1811; Cod 2/1, carta a Wellesley de 4.07.1811. Maties Ramisa, «La crisi patriota de $1811 \mathrm{i}$ el radicalisme», Butlletí de la Societat Catalana d'Estudis Històrics, n. XXVIII, (2017), 316-318. La Junta Superior de Cataluña se creó el 18 de junio de
} 
Codrington insistió en otros momentos sobre la necesidad de la venida de una división del ejército inglés a Cataluña. De hecho, creía que debería haberse enviado aquí la fuerza fundamental desde el principio. «Pero Cataluña era la Irlanda de España, en verdad», belicosa pero aciaga, «siempre rebelde contra la injusticia y la persecución» ${ }^{43}$. En adelante siguió insistiendo en el envío de una fuerza británica al Principado, pero era contrario a la creación de unidades de soldados autóctonos con mando inglés, al estilo de las de Roche y Wittingham, que Edwin Green quería imitar en Cataluña ${ }^{44}$.

A primeros de agosto de 1811, Codrington se encontró con el nuevo almirante de la flota mediterránea, Sir Edward Pellew, que había relevado hacía un par de semanas al anterior Sir Charles Cotton. Entre los dos hombres se estableció desde el principio una buena relación de confianza, y de hecho Pellew le dio a Codrington carta blanca para manejar los asuntos de Cataluña, que éste aprovechó ${ }^{45}$. Y es que el nuevo almirante comulgó desde el principio con buena parte de la visión que Codrington tenia de la situación en Cataluña, y en todo caso prefirió siempre dejar hacer al comodoro. Pellew se declaraba convencido que el espíritu de independencia permanecía indómito en el Principado, y que las causas de los fracasos residían en la indecisión, inactividad y desunión de los líderes españoles. Se manifestó bastante de acuerdo con el armamento general del campesinado propuesto por el comodoro ${ }^{46}$.

A primeros de octubre de 1811 el embajador Henry Wellesley acordó con Pellew pedir al gobierno inglés toda la ayuda posible para «los valientes habitantes de esa interesante provincia», dada la imposibilidad del gobierno español de prestarla. En estas mismas fechas Codrington -siempre interesado por la política- escribía al almirante que esperaba que Enrique O’Donnell, en su ida a Cádiz para integrarse en la Regencia,

1808 en Lérida para organizar la resistencia antinapoleónica; como las demás juntas provinciales españolas y la misma Junta Central, representaba el territorio, en este caso los trece corregimientos catalanes. A causa del hundimiento del gobierno español por la invasión, la Junta retuvo amplísimos poderes gubernativos, fiscales e incluso militares -propuso a casi todos los capitanes generales- hasta su desaparición a finales de 1812, reemplazada por la Diputación provincial. El pensamiento de sus vocales se caracterizaba mayoritariamente por un conservadurismo reformista. Véase Maties Ramisa, Politics $i$ militars a la Guerra del Francès, 1808-1814 (Lleida: Institut d'Estudis Ilerdencs, 2008), 107 y ss.

${ }^{43}$ NMM, Cod 2/1, carta de 20.09.1811. Lady Bourchier (ed.), Memoir, op. cit., vol.1, pp. 244-245.

${ }^{44}$ NMM, Cod 2/1, informe de 14.12.1811. Lady Bourchier (ed.), Memoir, op. cit., vol.1, pág. 252.

${ }^{45}$ Lady Bourchier (ed.), Memoir, op. cit., vol.1, pág. 239.

${ }^{46}$ NMM, Pel/17, cartas de Pellew de 18 y 22 julio, y 2 agosto 1811; Pel/20, carta de 12.08.1811. 
tendría con Pellew la atención que se merecía ${ }^{47}$ «promoviendo ansiosamente sus opiniones respecto de Cataluña».

De vez en cuando Sir Edward dejaba la estación catalana para recalar durante un tiempo en Menorca, con el objetivo de reavituallarse y reparar el Blake. Entonces era sustituido en el mando del escuadrón por el capitán Charles Adam, que habitualmente vigilaba las costas de Murcia. El día 7 de enero de 1812 Pellew le repitió al comodoro las instrucciones conocidas ${ }^{48}$ : confianza en el criterio de éste, protección de la costa de Cataluña, transmisión del máximo de información posible, comunicación directa con Henry Wellesley y armonía con las autoridades de Cataluña y especialmente con el agente militar británico coronel Edwin Green.

A finales de enero el almirante notificó a Sir Edward el envío por parte del gobierno británico de una gran provisión de armas y municiones al Principado; conocedor de las discrepancias entre el comodoro y Green, Pellew dijo no querer perder el tiempo en discutir el modo de distribuirlas. En la práctica dejó el reparto de las armas en manos de Codrington, que éste usaría según su criterio en el futuro. En la misiva, el almirante mostraba ya un cierto pesimismo sobre la situación de la provincia ${ }^{49}$ : «temo más de la desunión de los líderes y de la falta general de sistema en sus operaciones».

A pesar de la confianza en Codrington, el almirante tuvo que amonestarle en alguna ocasión. El agente militar Edwin Green, que sustituyó al general Charles W. Doyle en julio de 1811, no cayó bien a Sir Edward. Después de la pérdida de Tarragona, Green se refugió temporalmente en Peñíscola en medio de la desbandada general. Allí recibió muy pronto una enérgica requisitoria de Codrington, de una gran dureza verbal, para que regresara inmediatamente a Cataluña.

El agente militar manifestó sorpresa y estupor por el lenguaje del comodoro, se sintió ofendido y pidió protección a Pellew, a quien denunció «el lenguaje destemplado» de aquel, y «la repulsividad de las comunicaciones de ese caballero». El almirante desaprobó vigorosamente el tono de la carta de Codrington a Green, y el comodoro en

\footnotetext{
${ }^{47}$ NMM, Pel/11, carta de Wellesley de 8.10.1811; Pel/14, carta de Codrington de 10.10.1811.

${ }^{48}$ NMM, Pel/8, cartas de Pellew de 2 septiembre y 4 noviembre 1811, y de 7.01.1812. Lady Bourchier (ed.), Memoir, op. cit., vol.1, pp. 231-232. Codrington dejó Arenys de Mar el 24 de noviembre, y no volvió a la costa catalana hasta mediados de enero de 1812.

${ }^{49}$ NMM, Pel/17, carta de Pellew de 31.12.1812.
} 
su respuesta aseguró que en lo sucesivo adoptaría «ese tono de lenguaje hacia él que usted desea ${ }^{50} \gg$.

Pero la contención de Codrington duró poco. La ojeriza contra Green volvió a manifestarla al considerar que los servicios de éste como agente militar eran de poca utilidad, o al afirmar que el coronel no había tenido ningún papel en la conquista de las islas Medas. A Wellesley le confesaba que seguía sintiendo desconfianza contra el Military Agent. En noviembre de 1811 censuró la iniciativa de Green de levantar una unidad militar por cuenta propia, y así sucesivamente. El agente militar se sentía perseguido por Codrington ${ }^{51}$.

La Junta de Cataluña y el capitán general Luis Lacy habían pedido a los británicos ayuda para establecer un punto fortificado en la costa que asegurara las comunicaciones y el avituallamiento, después de la pérdida de Tarragona. Lacy se inclinó al final por las islas Medas, donde existía una pequeña guarnición francesa. Codrington ordenó al capitán Thomas que cooperara en la conquista, que se realizaría con una tropa española dirigida por el coronel Green. El asalto se efectuó con éxito el día 29 de septiembre de 1811; Lacy estableció una guarnición fija en la isla mayor, protegida por una corbeta inglesa. Sir Edward reconoció el valor estratégico de la operación $^{52}$.

Durante la segunda mitad de 1811 Sir Edward realizó dos viajes a Valencia para prestar ayuda ante la amenaza de invasión de Suchet, y en la práctica también para tomar parte en la brega que enfrentaba a Joaquín Blake con el Marqués de Palacio por el control de la provincia. Codrington se puso del lado del primero, al estimar que el segundo tendía al absolutismo, y tuvo un encontronazo con el Marqués en septiembre al negarse el comodoro a entregarle dos corsarios contrabandistas de Gibraltar. El capitán naval pidió a Henry Wellesley la destitución del Marqués de Palacio y denunció que los

\footnotetext{
50 NMM, Pel/13, cartas de 26 julio y 2 agosto 1811; Pel/11, carta de 5.08.1811; Cod 2/1, carta de 26.07.1811. A pesar de sus protestas, Green regresó inmediatamente a Cataluña después de la bronca de Codrington.

${ }^{51}$ NMM, Pel/17, carta de 2.09.1811; Cod 2/1, carta de 20 septiembre, y de 10 y 15 octubre 1811; Pel/14, carta de 4.10.1811; Pel/11, carta de 10.11.1811.

${ }^{52} \mathrm{NMM}$, Pel/ 13, cartas de 15 y 23 agosto, y de 1, 6 y 11 septiembre 1811; Pel/17, carta de 15.09.1811; Cod 5/5, informe del capitán Thomas de 1.10.1811; Pel/14, carta de 4.10.1811. El ataque a las islas Medas se llevó a cabo con una tropa española de 140 hombres, ayudados por fuertes dotaciones de marines de los navíos británicos de apoyo -el Undaunted, el Lavinia y el Blossom-, que traían morteros. El capitán Thomas alabó la bravura de los soldados españoles y la dirección del coronel Green, aunque más tarde él y Codrington se esforzaron por rebajar el papel del Military Agent.
} 
frailes realizaban una campaña para influir al pueblo valenciano contra Blake y los militares $^{53}$.

En esta época predominaba el entendimiento entre las autoridades de Cataluña a pesar del bajo momento de la resistencia después de la caída de Tarragona, y de la preocupación de Codrington por el contrabando de pequeñas embarcaciones de pesca que aprovisionaban Barcelona ${ }^{54}$. Lacy se afianzó en la capitanía del Principado e hizo resurgir al ejército regular; Sarsfield y el barón de Eroles dirigían sus principales divisiones. El comodoro consideraba a Lacy un general fuerte, mientras Blake, en Valencia, se mostraba débil. Sir Edward reiteraba las alabanzas al triunvirato militar gobernante, al que creía en la senda de buscar el armamento general de la población.

Codrington apoyaba de vez en cuando operaciones costeras; en una de ellas, a finales de enero de 1812, estuvo a punto de ser capturado por los franceses cerca de Tarragona $^{55}$. El capitán estaba orgulloso de la intimidad que mantenía con los jefes del ejército regular del Principado, y pensaba que su tarea de asistencia y consejo era imprescindible. Si Cataluña está bien auxiliada, afirmaba, puede establecer la libertad de la Península. El espíritu de los catalanes era inconquistable, y la caída de Tarragona no había supuesto la sumisión del Principado como él había predicho ${ }^{56}$, añadía.

\section{La campaña contra el capitán general Luis Lacy (1812)}

La armonía entre los jefes militares del ejército patriota de Cataluña, y del capitán general Luis Lacy con la Junta Superior duró hasta fines de 1811. En estas fechas afloraron de nuevo las endémicas tensiones entre el poder civil y el militar. También surgieron divergencias entre Sarsfield y el barón de Eroles. A la contienda se

\footnotetext{
${ }^{53} \mathrm{NMM}$, Pel/13, cartas de 3,4,5,6,7,8,10,11 y 16 septiembre 1811; Pel/14, carta de 26.10.1811; Pel/17, carta de 5.09.1811. Lady Bourchier (ed.), Memoir, op. cit., vol.1, pág. 243. Codrington, como otros oficiales de la armada británica, denunciaron sin éxito las actividades de los corsarios de Gibraltar, que bajo bandera inglesa realizaban un intenso contrabando de tabaco que mermaba mucho los ingresos de la hacienda española en el levante.

${ }^{54}$ NMM, Pel/14, carta de 1.12.1811; Cod 2/2, carta de 14.12.1811; Pel/13, cartas de 25 y 29 julio, 23 agosto y 1 septiembre 1811; Cod 2/1, cartas de 26.07.1811 y 19.08.1811. Codrington sospechaba que en el contrabando participaba el general Milans del Bosch.

${ }^{55} \mathrm{NMM}$, Pel/14, carta de 26.01.1812.

${ }^{56}$ NMM, Cod 2/2, carta de 8.11.1811. Lady Bourchier (ed.), Memoir, op. cit., vol.1, pp. 249-250.
} 
sumó con mucho brío el comodoro Edward Codrington desde finales de febrero de 1812, situándose del lado de la Junta del Principado y de Eroles.

En Cataluña, los desacuerdos entre el poder civil y el militar fueron constantes desde el comienzo de la guerra, y a veces desembocaron en auténticas crisis. No de otra manera se pueden calificar las dimisiones de los capitanes generales Juan Miguel de Vives, Joaquín Blake y Enrique O’Donnell. Los políticos aportaban un sentido civilista y el convencimiento de que representaban el conjunto de la población, el bienestar de la cual defendían; querían que la guerra hiciera los mínimos estragos, que la economía no se ahogara del todo y que los militares fueran eficaces.

Éstos lo subordinaban todo a las necesidades de la guerra y se sentían molestos por las continuas interferencias de las juntas en las decisiones de su ámbito ${ }^{57}$. Con un árbitro lejano y a menudo inoperante -el Estado-, el conflicto estaba servido. En la etapa de Lacy las fricciones con el poder civil fueron debidas a la oposición de la Junta Superior a la supresión de las exenciones por dinero en el reclutamiento, a la mobilización de parte de los reservistas, al intento de Lacy de controlar los impuestos, y sobre todo a su orden de incorporar todas las partidas y guerrillas al ejército regular.

Desde el principio, para Sir Edward el enemigo a batir fue Luis Lacy, del cual pidió la destitución inmediata. La razón era el incumplimiento de las promesas de armamento general del pueblo que Codrington había entendido que se iban a llevar a cabo; de hecho, la política de Lacy iba en sentido contrario, y estaba procediendo a la militarización de las partidas guerrilleras ${ }^{58}$ para formar un ejército más disciplinado.

La anterior simpatía de Codrington por Lacy se desvaneció. La animadversión se extendió a Sarsfield. El comodoro volvía a postular a Eroles como capitán general de Cataluña. Su objetivo era político: conseguir que Cataluña se independizara del poder de Napoleón y que al mismo tiempo efectuara una revolución. Ilustraba a sus interlocutores con los derechos y libertades que proclamaba la nueva constitución de Cádiz, que debían aplicarse a Cataluña para poner fin al despotismo de Lacy ${ }^{59}$.

\footnotetext{
57 Estos aspectos son desarrollados en Antoni Moliner Prada, La Catalunya resistent a la dominació francesa (1808-1812) (Barcelona, Edicions 62, 1989), 63 y ss.

${ }^{58} \mathrm{NMM}, \mathrm{Pel} / 14$, informe de Codrington de 22.02.1812.; Cod 5/5, carta de 26.02.1812.

${ }^{59}$ NMM, Cod 2/1, cartas de 27 febrero y 10 abril 1812; Pel/17, carta de Pellew de 20.04.1812. Lady Bourchier (ed.), Memoir, op. cit., vol.1, pp. 267, 269, 273, 274.
} 
El barón de Eroles tenía entonces 28 años. Al empezar la guerra había abandonado los estudios de derecho y se había incorporado al cuerpo de voluntarios de Talarn. Participó en la defensa de Gerona, donde fue hecho prisionero y llevado a Francia. Escapó pronto de la cárcel y se reincorporó al ejército patriota de Cataluña, donde ascendió meteóricamente: a principios de 1813 ya era mariscal. Intrépido y valeroso, buen militar y conductor de hombres nato, el barón tenía la protección de la Junta de Cataluña y un pensamiento absolutista. Empezó a aspirar a la capitanía general ya en tiempos de Lacy, pero lo disimuló con una apariencia de reserva y sumisión. En cambio, su enfrentamiento con Francisco de Copons, sucesor de Lacy, fué ya franco ${ }^{60}$.

Sir Edward extendió la desconfianza que sentía por Lacy al intendente y a sus funcionarios, a quienes acusaba de corruptos. Denunciaba el comercio ilegal de la costa para abastecer la Barcelona napoleónica ${ }^{61}$, en el que veía connivencias de los empleados del intendente y de comerciantes como José Arquer y Gaspar de Remisa.

El comodoro procuró ganarse al poder político de la provincia para su causa. A primeros de abril de 1812 mantuvo contactos con dos vocales de la Junta de Cataluña y salió satisfecho. Ya en febrero había hablado con Elías Arxer, el delegado que la Junta enviaba a Cádiz para explicar al gobierno español la situación de la provincia. Arxer le había causado muy buena impresión, le había parecido que representaba la voz del Principado, y también estaba de acuerdo con las destituciones de Lacy y Sarsfield ${ }^{62}$.

El principal interlocutor del comodoro en la Junta Superior fue el activo comerciante gerundense Francisco Ferrer y Font, de pensamiento liberal y librecambista. Estableció una relación especial con él al «encontrarle el tipo correcto de personaje, y escuchar que él es el único de la Junta que tiene la resolución de expresar sus sentimientos reales». La Superior anunció a Sir Edward que sintonizaba con sus propuestas, pero a mediados de mayo éste se sorprendió al enterarse que Lacy había

\footnotetext{
${ }^{60}$ La hoja de servicios del barón de Eroles en el ejército español se halla en A. Martin-Lanuza, Diccionario biográfico, op. cit., pp. 438-439. El Barón de Eroles (1784-1825) se llamaba Joaquín de Ibáñez-Cuevas y de Valonga. Durante el Trienio fue deportado a Mallorca, de donde escapó para organizar la Regencia absolutista de Urgel. Derrotado por los liberales, huyó a Francia en 1822, y regresó con la expedición de los Cien Mil Hijos de San Luís. Murió de enfermedad en 1825 cuando se encargaba de reconstruir el ejército real español.

${ }^{61} \mathrm{NMM}$, Cod 5/5, cartas de 5 marzo y 9 mayo 1812; Cod 2/1, cartas de 18.05.1812 y 24.10.1812; Cod 2/2, carta de 23.05.1812; Pel/15, carta de 5.06.1812.

${ }^{62} \mathrm{NMM}$, Cod 5/5, carta de 26.02.1812; Cod 2/1, carta de 27.02.1812; Pel/15, carta de 8.04.1812. Lady Bourchier (ed.), Memoir, op. cit., vol.1, pp. 273.
} 
sido promocionado al grado de teniente general, y al cargo de capitán general definitivo de Cataluña. Empezó a sospechar que algunos políticos catalanes empleaban un doble lenguaje, y a considerar a Elías Arxer un espía del capitán general ${ }^{63}$.

A mediados de junio de 1812 Codrington tuvo otro grato encuentro con Eroles y con el almirante Pellew en Vilanova i la Geltrú ${ }^{64}$. «El almirante le dejó enterarse de todos nuestros secretos -explica Sir Edward a su mujer-, y él y yo, por lo tanto, hablamos sin reservas, y tuvimos similares sentimientos en todas nuestras propuestas respecto a Cataluña».

El leitmotiv principal del comodoro, el armamento de todo el pueblo, tenía su correlato en la distribución de las armas. Desde principios de 1812 el gobierno británico había enviado una considerable remesa al Principado con el fin de reavivar allí la resistencia patriótica. El contingente era considerable: 7.629 barriles de pólvora, 40.000 mosquetes, 450.000 pedernales, 7.560 .000 cartuchos, además de accesorios y munición. El almirante Pellew se había desentendido de su distribución ${ }^{65}$ y la había otorgado de facto a Codrington, el cual la utilizó sin ambages para imponer sus puntos de vista.

El comodoro lo advirtió desde el principio a las autoridades de Cataluña en marzo: la condición para entregar las armas era la ejecución de un armamento general de la población. A partir de entonces hizo entregas selectivas a diversos militares y guerrilleros, a los corregimientos y a la Junta, pero nunca a Lacy. A primeros de marzo suministró una cantidad a la partida del «valiente» José Manso, y más adelante lo hizo con Milans y con otras partidas guerrilleras en secreto.

En junio de 1812 Codrington disponía de un gran stock de armamento y se lo ofreció a la Junta Superior ${ }^{66}$, pero se sorprendió que la Junta le comunicara que todavía había soldados sin armas. De acuerdo con sus cálculos, al ejército regular no le podía faltar armamento de ninguna manera. «Según esto, parece que las quejas contra el

\footnotetext{
${ }^{63}$ NMM, Cod 2/1, cartas de 10 abril, 4 y 15 mayo, y 11 y 19 septiembre 1812; Pel/15, carta de 4.05.1812. Lady Bourchier (ed.), Memoir, op. cit., vol.1, pp. 273, 282. El 11 de julio se habían presentado en el Blake un grupo de «ladies» conocidas de Francisco Ferrer; Sir Edward las había invitado a bailar y a desayunar en el navío, con gran regocijo de los oficiales jóvenes. Por otro lado, Codrington había aprovechado las buenas relaciones con la Junta para denunciar la presunta corrupción de los empleados de la indendencia del ejército.

${ }^{64}$ Lady Bourchier (ed.), Memoir, op. cit., vol.1, pp. 279-280. Al día siguiente Sir Edward cenó con el Barón de Eroles, como siempre con humo y comida grasienta, cosas que disgustaban al capitán naval.

${ }^{65}$ NMM, Pel/11, carta de Lord Liverpool a Pellew de 14.01.1812; Pel/17, carta de Pellew de 31.01.1812.

${ }^{66} \mathrm{NMM}, \mathrm{Pel} / 20$, carta de 8.02.1812; Cod 5/5, cartas de 9 marzo y 9 junio 1812; Pel/17, carta de 20.04.1812; Cod 2/1, carta de 18.06.1812. Lady Bourchier (ed.), Memoir, op. cit., vol.1, pág. 267.
} 
campesinado de que pierden o venden sus armas deberían aplicarse más adecuadamente a las tropas regulares». Fueran particulares o soldados, es cierto que a lo largo de la guerra funcionó un comercio clandestino de reventa de las armas inglesas. También lo es que el capitán general y la Junta del Principado siguieron pidiendo pertrechos militares durante todo el año $1812^{67}$.

El comodoro persistió obstinadamente en su negativa a proporcionar armas al capitán general. La opinión de Edwin Green fue descalificada por Sir Edward en términos agrios ${ }^{68}$, y no fue tenida en cuenta por el almirante. En un informe de junio de 1812, Green explicó a Pellew su punto de vista sobre la distribución de armas y sobre la actuación de Codrington $^{69}$ : las armas deberían entregarse a los oficiales expresamente enviados por el capitán general, a los gobernadores de los corregimientos o al mismo Green, y en el acto deberían redactarse recibos oficiales. Cualquier otro sistema de entregas en la costa abría la puerta a desórdenes y errores. Era mejor confiar en la responsabilidad de la persona que comandaba la provincia.

Las fuentes de información de Codrington, continuaba Green, eran de personas de intenciones patrióticas pero altamente interesadas, confusas, limitadas o desordenadas; uno de ellos era un capitán de partisanos, «un Hombre de fortuna desesperada, insubordinado y (...) poco mejor que un líder de Bandidos». Y añadía: «E1 modo en que el Capitán Codrington juzga el estado de las cosas en esta provincia, y el lenguaje en el que escribe a las autoridades, bajo impresiones parciales, debo considerar que conduce a mucha confusión, y a pesar de sus celosas intenciones, abre una puerta involuntariamente a tergiversaciones al Gobierno de $\mathrm{Su}$ Majestad, ya sea por sus Comunicaciones oficiales o privadas»».

Mientras tanto, desde mediados de abril de 1812 iba tomando cuerpo el proyecto de enviar una expedición militar británica desde Sicilia a las costas de Cataluña, sugerida por Wellington, con el fin de operar una actuación que le beneficiara y controlar la próxima cosecha, evitando que cayera en manos de los imperiales. En junio

\footnotetext{
${ }^{67}$ NA, Fo 72/127, carta de Castlereagh de 23.05.1812. NMM, Pel/11, cartas de Green y Lacy de 23 y 29 febrero 1812; Pel/12, carta de Green de 19.05.1812.

${ }^{68}$ NMM, Pel/11, cartas de 7 y 15 marzo 1812; Pel/12, carta de 19.05.1812; Cod 2/1, cartas de 11 septiembre y 24 octubre 1812, y 3.11.1812; Pel/18, carta de 27.10.1812; Cod 2/2, carta de 6.12.1812.

${ }^{69}$ NMM, Pel/12, informe de Green a Pellew de 4.06.1812.
} 
comenzaron a llegar soldados a Menorca ${ }^{70}$. Los informes de Codrington de julio de 1812 derrochaban entusiasmo: los catalanes estaban electrificados por la venida del ejército inglés y los enemigos deprimidos, habría un apoyo masivo de la población tal como había apuntado el Barón de Eroles. Sería fácil tomar Tarragona e incluso Lérida ${ }^{71}$.

El día 31 de julio la flota británica de la expedición con 10.000 hombres ancló delante de Palamós, y el Barón de Eroles, desde el Blake de Codrington, estalló de alegría. Pero el general Maitland y los oficiales de la expedición no vieron claro el desembarco por debilidad propia y falta de apoyo -la tropa móvil francesa podía ser de más de 15.000 hombres-. Después de interrogar a Codrington, Eroles, Lacy y Sarsfield, decidieron marchar hacia Alicante. La decepción del comodoro y de muchos líderes catalanes fue considerable; en cambio, el contraalmirante Benjamin Hallowell atribuyó el fracaso a la falsedad de los informes de Codrington ${ }^{72}$-basados sólo en las opiniones del Barón de Eroles-, que habían hecho creer a Pellew y a Bentinck en la debilidad de los enemigos en Cataluña y en el apoyo unánime que tendría la expedición aquí.

En el último tramo de 1812 se produjo la culminación de la campaña contra el capitán general Luis Lacy por parte de la Junta de Cataluña y sectores de las élites, auxiliadas por el comodoro inglés. Éste y la Junta pidieron -por separado- la destitución del capitán general. En las misivas, el capitán inglés explicaba los $\operatorname{argumentos}^{73}$ : despotismo, corrupción, inactividad y posible trato con el enemigo, medidas en perjuicio de Eroles, aversión de Lacy contra los ingleses, etc.

La estrategia de la Junta Superior -de la que parece que Codrington fue dejado relativamente de lado- consistió en denunciar a las Cortes y a la Regencia las

\footnotetext{
${ }^{70}$ BL (BRITISH LIBRARY, Londres), Add MS 75959, carta de Hallowell de 13.04.1812. NMM, Pel/20, cartas de Pellew de 15.04.1812 y 23.06.1812; Pel/12, carta de 9.06.1812.

${ }^{71}$ BL, Add MS 75959, carta de Hallowell de 24.07.1812. NMM, Cod 2/1, informes de 27 junio y 13 y 19 julio 1812; Cod 2/2, informes de 10 y 27 julio 1812. A diferencia de Codrington, el contraalmirante Benjamin Hallowell, que venía con la expedición, era pesimista sobre un desembarco en Cataluña, donde los franceses eran fuertes.

${ }^{72}$ NA, Fo 72/131, carta de 30.07.1812. BL, Add MS 75959, informe de Hallowell de 30.08.1812. NMM, Pel/15, informe de 31.07.1812. Lady Bourchier (ed.), Memoir, op. cit., vol.1, pp. 284-285. Nick Lipscombe, Wellington's Eastern Front, op. cit., pp. 84-85. Sir William Francis Patrick Napier, History, op. cit., vol. 4, 87-91.

${ }^{73} \mathrm{NMM}$, Cod 2/1, cartas de Codrington de 4 septiembre; 1, 5, 12, 18, 20, 24, 25, 27 octubre; 3, 6 y 12 noviembre 1812; Cod 2/2, cartas de 13 y 25 noviembre; 2 diciembre 1812. Lady Bourchier (ed.), Memoir, op. cit., vol.1, pp. 294-297. En noviembre de 1812, después de la retirada de Wellington de Burgos, Codrington vio que se esfumaban las esperanzas de la llegada de un ejército inglés a Cataluña y se sintió abatido y solo, rodeado de vicio y corrupción; entonces tomó la decisión de pedir el regreso a Inglaterra.
} 
arbitrariedades de Lacy por medio de los diputados catalanes y por enviados como Elías Arxer y Antonio Barata, en pedir la separación de los poderes político y militar tal como establecía la Constitución, y en solicitar el relevo del capitán general. Los promotores de la conspiración contra Luis Lacy parece que fueron el Barón de Eroles, Francisco Ferrer, Antonio Barata y Antonio Castells. El papel de Arxer no está claro.

En cambio, la estrategia de Lacy, reputado de liberal, estribó en aprovechar las ambigüedades de la legislación para concentrar en su persona el mando militar y político provincial. Y lo consiguió. El 6 de octubre de 1812 fue nombrado jefe político interino de la provincia de Cataluña, organizó las elecciones de diputados y de los ayuntamientos constitucionales, y el 30 de noviembre cesó a la Junta Superior para sustituirla por una Diputación Provincial ${ }^{74}$. Pero fue una victoria pírrica, porque la clase política del Principado consiguió su destitución el 8 de diciembre de 1812 .

Las denuncias de Codrington contra Lacy no parece que llegaran mucho a los altos estamentos británicos. El contraalmirante Hallowell consideraba al capitán demasiado apasionado y parcial, y el embajador Wellesley casi no mencionaba las ideas y las graves sospechas que Codrington le transmitía. En esta época, el embajador sólo se hace eco «de algún descontento» que se había levantado contra Lacy por el hecho de desarmar parte de las fuerzas irregulares. De hecho, a primeros de diciembre de 1812 el propio Sir Edward exponía a Wellesley la decepción por no haber recibido aún ninguna respuesta a las peticiones que había hecho sobre la destitución de $\operatorname{Lacy}^{75}$.

Por fin, el 5 de diciembre Codrington tuvo una alegría al saber que Lacy había sido cesado; parecía además que Eroles -un partidario de los ingleses- sería puesto en su $\operatorname{lugar}^{76}$. En realidad, más que la presión del comodoro, fue determinante en la destitución de Lacy el empuje de parte de las élites catalanas opuestas a su política, y las extralimitaciones despóticas del propio capitán general, que había suprimido a la fuerza la Junta Superior y encarcelado al intendente Oteyza.

\footnotetext{
74 Para el proceso de implantación de la constitución de Cádiz en Cataluña, véase M. Ramisa, «La aplicación de la Constitución de Cádiz en Cataluña (1812-1814)», Spagna contemporanea, n. 41 (2012), $7-27$.

${ }^{75}$ NA, Fo 72/129, informe de Wellesley a Castlereagh de 22.03.1812. NMM, Cod 2/2, carta de 2.12.1812.

${ }^{76}$ Lady Bourchier (ed.), Memoir, op. cit., vol.1, pág. 297.
} 


\section{La devoción por el Barón de Eroles}

El mismo día de la caída de Tarragona en manos del general Suchet, el 28 de junio de 1811, Edward Codrington descubrió a la persona destinada a salvar a Cataluña: el joven militar de origen aristocrático Joaquin de Ibáñez-Cuevas y de Valonga, barón de Eroles, nacido en Talarn veintisiete años antes. Había subido al Blake con intención de ponerse al frente de cuatro mil hombres de la guarnición y acabar con el sitio, y desde este buque de línea conoció el asalto y toma de la capital patriota.

Delante de Codrington el barón juró que a partir de entonces «cada acción suya y cada pensamiento serían por la libertad de su país». El capitán quedó impresionado por estas palabras, y desde ese momento se convenció que Eroles era la persona que la provincia necesitaba: «mi corazón sangra por él casi tanto como por la misma Cataluña, con la que está identificado» ${ }^{77}$. Para Sir Edward, el barón encarnaba el verdadero patriotismo. Y tres días después ya lo proponía al almirante Cotton como nuevo general en jefe, a pesar de que la Regencia acababa de nombrar a Luis Lacy. Ante las insistentes propuestas del comodoro, Eroles siempre se negó: él no sería mejor que Lacy, contestaba, y la remoción de éste causaría la ruina de Cataluña. En septiembre de 1811 Codrington le llegó a ofrecer la ayuda de una división inglesa si aceptaba el cargo ${ }^{78}$. Pero eran tiempos de concordia entre las autoridades del Principado y el comodoro se dio cuenta de que no debía estorbar la consolidación de Lacy ${ }^{79}$.

En febrero de 1812 llegaron los desacuerdos, que ya no abandonarían el escenario político catalán hasta el relevo de Lacy casi un año después. A mediados de mes el comodoro denunciaba furiosamente a Lacy por el desarme de las partidas y su inclusión en el ejército regular; estas medidas provocaban desasosiego y deserción.

\footnotetext{
${ }^{77}$ NMM, Cod 2/1, carta de 29.06.1811; Cod 5/5, cartas de 29.06.1811. Lady Bourchier (ed.), Memoir, op. cit., vol.1, pp. 230-231.

${ }^{78}$ NMM, Cod 2/1, carta de 1 julio y 19 agosto 1811; Lady Bourchier (ed.), Memoir, op. cit., vol.1, pp. $236,243-245$.

${ }^{79}$ NMM, Cod 2/1, informe de 15.01.1812. Pel/11, informe de Green de 11.11.1811. Lady Bourchier (ed.), Memoir, op. cit., vol.1, pp. 247, 251, 254-257. El 21 de noviembre de 1811 el barón de Eroles le regaló a Sir Edward unas espuelas de plata dorada que había abandonado el general francés La Tour cuando tuvo que salir corriendo de Igualada ante el avance de los españoles.
} 
«Nada excita más la sospecha de los catalanes que un intento de desarmarlos», escribía a Henry Wellesley; el descontento ambiental podría provocar un estallido ${ }^{80}$.

Codrington regresó con fuerza a su anterior petición de que Eroles debía ser el general en jefe en Cataluña, y la reiteró a todos sus interlocutores hasta la saciedad. En esta postura se sintió cada vez más acompañado por la Junta Superior de Cataluña, aunque hasta después del verano de 1812 las promesas de ésta al capitán inglés solo fueron buenas palabras ${ }^{81}$. El optimismo del barón de Eroles contagió al ya predispuesto Sir Edward y al almirante Pellew, de cara al previsto desembarco de tropas anglosicilianas en Cataluña durante el verano. Por extensión, también alcanzó al gobernador de Sicilia Sir William Bentinck ${ }^{82}$.

La amistad entre Codrington y Eroles se estrechaba: «The Baron is my messmate», declaraba el comodoro en julio. Ambos compartieron la satisfacción por dos hitos en las acciones de lo que podría calificarse de guerra sucia impulsada por Lacy contra los franceses: la voladura del castillo de Lérida y el envenenamiento del pan de la guarnición de Barcelona. En agosto de 1812, Eroles seguía insistiendo en la alta moral patriótica del Principado ${ }^{83}$ a pesar del fiasco de la expedición anglosiciliana.

Durante los meses siguientes Codrington continuó esforzándose en desprestigiar a Lacy y ensalzar a Eroles. Además, según el comodoro, Lacy estaba extremadamente molesto por la «ilimitada confianza que la gente percibe entre Eroles y yo». Sir Edward y el barón -a quien el capitán llamaba a veces "the little Baron" por su baja estaturapasaron un día agradable de caza el 19 de octubre y cenaron en la playa ${ }^{84}$. Conocida la destitución de Lacy a principios de diciembre de 1812 y su probable sustitución por el

\footnotetext{
${ }^{80}$ NMM, Cod 5/5, informe a Wellesley de 12.02.1812; Pel/11, duro informe de Green contra Lacy y Sarsfield de 22.02.1812. El Military Agent Edwin Green compartió entonces con Codrington la necesidad de que Lacy fuera reemplazado por Eroles, pero pronto suavizó su postura.

${ }^{81}$ NMM, Pel/11, carta 22 abril e informes de 5 y 6 mayo 1812; Pel/17, carta de 9.05.1812; Pel/14, carta de 22.02.1812; Cod 5/5, carta de 26.02.1812; Cod 2/1, carta de 25.04.1812.

${ }^{82}$ NMM, Pel/11, carta de 9.05.1812; Pel/20, carta de 14.05.1811; Cod 2/1, cartas de 18 y 28 mayo, y 27 junio 1812 .

${ }^{83}$ NMM, Cod 2/2, carta de 20.07.1812; Cod 2/1, cartas de 19 julio y 21 y 24 agosto 1812; Lady Bourchier (ed.), Memoir, op. cit., vol.1, pp. 282-284. En esta época, Sir Edward seguía trabajando con interés en la perspectiva de la regeneración de Cataluña.

${ }^{84} \mathrm{NMM}$, Cod 2/1, cartas de 28 agosto, 1,5, 12, 18, 20 y 24 octubre 1812; Pel/16, carta de 27.09.1812. Lady Bourchier (ed.), Memoir, op. cit., vol.1, pp. 290-291.
} 
barón de Eroles ${ }^{85}$-que acabó siendo un breve interinato-, el optimismo del comodoro renació. Aunque había solicitado su relevo al almirante, escribía ahora de vez en cuando que querría quedarse.

Sir Edward asumía ahora de alguna manera el papel de tutor del joven futuro general en jefe. El inglés quería ser útil a su amigo. «Considerando que Vd. cambiará enteramente el systema en tal modo que nos podamos aprovechar de los deseos patrióticos de sus compatriotas», le escribía en español; la desunión de los jefes militares ha disgustado al pueblo de Inglaterra, agregaba, y ha separado al pueblo del ejército en el Principado ${ }^{86}$. Debía restaurarse la unión. Codrington defendió al anciano intendente Oteyza, perseguido por Lacy. Al oír en enero de 1813 el rumor del nombramiento de Francisco Copons como capitán general de Cataluña ${ }^{87}$, consideró que no sería beneficioso para el Principado; en cambio, añadía, la jefatura del nativo Eroles impulsaría la libre Constitución por la cual había hecho tantos sacrificios.

El 1 de febrero de 1813 Luis Lacy entregó interinamente el mando al barón de Eroles; el día anterior Codrington había conocido su relevo al frente de la estación naval de Cataluña, de la que se haría cargo el capitán Charles Adam. «Siento bastante el ausentarme de Cataluña», escribió Sir Edward. Pero quería despedirse en persona del barón, y continuó navegando algunas semanas más por aguas del Principado. Por fin Codrington pudo abrazar personalmente a Eroles el día 24 de febrero en Altafulla ${ }^{88}$, antes de partir hacia Menorca y después a Inglaterra.

\section{EPÍLOGO}

Durante el viaje de vuelta a Inglaterra, Codrington todavía realizó gestiones y recogió informaciones sobre el Principado. Aconsejó a John Murray que concertara operaciones con Eroles, se entrevistó con Sarsfield, discutió con Hallowell, se hizo eco

\footnotetext{
${ }^{85} \mathrm{NMM}, \mathrm{Pel} / 16$, carta de 8.11.1812; Pel/18, carta de 1.12.1812; Cod 2/2, cartas de 6, 9, 15 y 24 diciembre 1812; Cod 2/1, carta de 25.10.1812. Lady Bourchier (ed.), Memoir, op. cit., vol.1, pp. 297, 299.

${ }^{86} \mathrm{NMM}, \mathrm{Pel} / 12$, carta de 27.12.1812; Pel/16, carta de 31.12.1812; Cod 2/2, cartas de 25 y 30 diciembre 1812, y 13 y 14 enero 1813. Lady Bourchier (ed.), Memoir, op. cit., vol.1, pp. 301-303. Codrington consideraba al militar-guerrillero José Manso "a Catalan Soldier of the Revolution".

${ }^{87} \mathrm{NMM}$, Pel/16, carta de 22.01.1813; Cod 2/2, cartas de 15,18,20, 21 y 22 enero 1813. En cambio, el coronel Francisco Javier Cabanes, jefe del estado mayor de Copons, le causó al capitán naval una buena impresión.

${ }^{88} \mathrm{NMM}$, Cod 2/2, cartas de 1,4, 8, 9, 12, 20, 24 y 28 febrero 1813; Pel/16, carta de 6.02.1813.
} 
de las acusaciones de ladrón y cobarde contra Copons y siguió la abolición de la Inquisición. Por fin el 27 de marzo de 1813 llegó a Cawsand Bay, Cornwall ${ }^{89}$.

El almirante Pellew, diversas autoridades hispanas y el embajador Wellesley le dirigieron breves y elogiosas cartas de despedida. Pero parece que el esperado reconocimiento del gobierno británico a los servicios de su etapa española nunca le llegó. Todavía en 1818 Sir Edward escribía al Duque de San Carlos, embajador español en el Reino Unido, quejándose de que no había obtenido ningún agradecimiento del príncipe regente, y que Castlereagh no le había contestado una carta. Henry Wellesley le había prometido que haría gestiones a su favor, y no lo había cumplido ${ }^{90}$.

De todos modos, Edward Codrington siguió ascendiendo en su carrera naval. En 1814 fue promovido a contraalmirante y participó en la guerra contra los Estados Unidos; en 1825 se convirtió en vicealmirante, y en diciembre de 1826 fue nombrado comandante en jefe de la flota mediterránea, al frente de la cual participó en la batalla de Navarino el 20 de octubre de 1827, otro de sus hitos bélicos que le reportó grandes honores. En dicha acción naval Codrington dispuso de gran superioridad sobre la flota turca, a la que destrozó, favoreciendo así la independencia de Grecia ${ }^{91}$.

A pesar de todo, el gobierno conservador británico consideró precipitada e inoportuna la actuación de Sir Edward en Navarino, y le destituyó del cargo. Codrington regresó a Inglaterra y reivindicó su comportamiento, con la ayuda de los whigs. Entre 1832 y 1839 entró en el Parlamento británico y se situó del lado de los reformadores. En 1837 fue finalmente nombrado almirante, y terminó su carrera naval como comandante en jefe de Portsmouth en 1842. Murió en 1851.

Edward Codrington fue un marino comparable de alguna manera a Thomas Cochrane. En ambos el radicalismo político tuvo una fuerte influencia en sus carreras, aunque el segundo se distinguía por un impetuoso activismo militar que Sir Edward no poseía. De todos modos, éste coincidía con la idea de Cochrane de que Gran Bretaña

\footnotetext{
${ }^{89}$ NMM, Cod 2/2, cartas de 1, 4, y 9 marzo 1813. Lady Bourchier (ed.), Memoir, op. cit., vol.1, pág. 308.

${ }^{90}$ NA, Fo 72/143, carta de despedida de Pedro Labrador. NMM, Cod 5/3, cartas de despedida de 5 y 8 marzo 1813 de José Anglasell, Pedro Labrador y la Regencia del Reino; Pel/18, despedida de Pellew; Cod 2/2, cartas de Codrington al Duque de San Carlos de 16 noviembre y 20 diciembre 1818. Lady Bourchier (ed.), Memoir, op. cit., vol.1, pág. 499. Sir Edward aseguró que Lord Castlereagh nunca había entregado al príncipe regente la carta elogiosa de la Regencia española.
}

91 Marjie Bloy, «Sir Edward Codrington, (1770-1851)», A web of English History; http://www.historyhome.co.uk/people/cod-ton.htm (2016) 
debía ser mucho más enérgica en la guerra contra Francia. Podría considerarse que Codrington aplicó un sesgo político excesivo a su actuación durante la Peninsular War en Cataluña, especialmente en su implacable campaña contra el capitán general Luis Lacy y en su reivindicación del Barón de Eroles.

Es muy posible que el comodoro tuviera un notable grado de desconocimiento de la situación política real del Principado mientras navegaba por sus aguas. Su arraigada ideología le hacía propenso a las ideas preconcebidas; además, pasaba buena parte del tiempo en el mar, y cuando bajaba a tierra mantenía contactos con un reducido número de personajes seleccionados. Muchos de ellos le decían lo que el capitán quería oír, y después no siempre cumplían con lo que habían declarado. La Junta Superior de Cataluña y el delegado Elías Arxer le prometieron durante mucho tiempo seguir sus ideas sin llegar a ejecutarlo en la práctica.

En cierto modo le sucedió lo mismo con el barón de Eroles. Ni la amistad que trabaron ambos hombres, ni los continuos consejos de Sir Edward consiguieron que el barón se decidiera a hacer una oposición activa contra el capitán general y se postulara para ocupar este cargo. Cabe concluir de ello que el comodoro tuvo una menor influencia en los acontecimientos de la que él mismo imaginaba.

Otra muestra de la disociación de Codrington con la situación real del Principado -y también de la escasa influencia que la ideología política tenía durante la guerra de la Independencia- la encontramos en la elección de las filias y las fobias del capitán naval. La enemistad con Lacy -cuando era ya conocida la afinidad de éste con los liberales- y la admiración que profesaba por el barón de Eroles y por José Manso ${ }^{92}$-cuando el primero se mostró partidario del absolutismo y el segundo del moderantismo años después- se compadecen mal con el liberalismo radical de Sir Edward.

El capitán Codrington ejerció una activa interferencia en la gobernación del Principado de Cataluña durante los años en los que patrulló sus costas con el escuadrón de su mando. Esta actitud fue debida a su propia personalidad, a sus robustas convicciones políticas, al deseo de ayudar a regenerar el país y a cierto sentimiento de superioridad británica. Por otra parte, demostró en su trayectoria -también en Cataluñaun valor personal evidente y una gran persistencia en los objetivos que se asignaba.

\footnotetext{
${ }^{92}$ Desde luego, José Manso no era “a Catalan Soldier of the Revolution”, como había escrito Codrington.
} 
Sus habilidades como marino también son indiscutibles. Se enfrentó a grandes ventoleras y tempestades, al sitio de Tarragona y a diversas acciones costeras en coordinación con fuerzas españolas. Se conocía al dedillo la costa catalana, hasta el punto que podía desembarcar de noche en cualquier punto de ella si se lo proponía. A ello hay que añadir el humanitarismo, como demostró con los refugiados fugitivos de Tarragona $^{93}$, y el amor por su mujer y los hijos. La estima que Codrington sentía por Cataluña era sincera y profunda, como revelan sus informes y correspondencia. Siempre creyó en el patriotismo de los catalanes y en la victoria final, aunque él les adjudicaba un deseo de libertad y un sentimiento antiabsolutista que seguramente no se correspondía con la realidad social del momento.

Los resultados militares de la gestión del comodoro Codrington en el Principado no son muy destacables. Ayudó en el transporte de tropas, en el bloqueo de Barcelona y otros puertos, en el aprovisionamiento de intendencia y en diversos ataques o acciones en puntos del litoral, entre los que destaca la defensa de Tarragona. Pero también se inmiscuyó y participó en las disputas entre las autoridades de la región, cosa que no favorecía la marcha de la guerra. Quizás por ello ni los biógrafos, ni los historiadores, ni él mismo, resaltaron demasiado su etapa dirigiendo el escuadrón naval en las costas españolas de Cataluña durante la Peninsular War.

\section{FUENTES Y BIBLIOGRAFIA}

\section{Archivos}

British Library, (BL, Londres). Secciones y legajos: Add MS 75959.

National Archives (NA, Kew, Londres). Secciones y legajos: CO 173/2, Fo 72/127, Fo 72/129, Fo 72/131, Fo 72/143.

National Maritime Museum (NMM, Greenwich, Londres). Secciones y legajos: Pel/8, Pel/11, Pel/12, Pel/13, Pel/14, Pel/15, Pel/16, Pel/17, Pel/18, Pel/20, Cod/2/1, $\operatorname{Cod} / 2 / 2, \operatorname{Cod} / 5 / 3, \operatorname{Cod} / 5 / 5$.

\footnotetext{
${ }^{93}$ Lady Bourchier (ed.), Memoir, op. cit., vol.1, pp. 234, 305. Cuando trasladaba refugiados de Tarragona, Codrington se enfrentó con un joven oficial español que se negaba a responder a una pobre mujer sobre la suerte del marido de ésta. El capitán naval despreciaba el orgullo masculino que los españoles desplegaban con las mujeres.
} 


\section{Bibliografía:}

Bloy, Marjie. A web of English History; http://www.historyhome.co.uk/people/codton.htm (2016) (consultado el 25.08.2019)

Bourchier, Lady (ed.), Memoir of the life of Admiral Sir Edward Codrington: With selections from his public and private correspondence, 2 vols. London: Longmans, Green and Co., 1873.

Collingwood, Cuthbert. The Private correspondence of Admiral Lord Collingwood. London: Edited by Edward Hughes, 1957.

Esdaile, Charles. "La repercusión de la guerra de 1808 en Gran Bretaña», Cuadernos dieciochistas, Ediciones Universidad de Salamanca, 2007.

-- Fighting Napoleon. Guerrillas, Bandits and Adventurers in Spain 1808-1814. New Haven \& London: Yale University Press, 2004.

Fortescue, J.W. A History of The British Army, 13 vols. London: Macmillan and Co., Limited St. Martin's Street, 1910.

Gómez de Arteche, José. Guerra de la Independencia. Historia militar de España de 1808 á 1814, 14 vols. Madrid: Imprenta Asilo Huérfanos, 1868-1903.

Hicks, Peter. Napoleon.org, The History website of the Fondation Napoleon; (2016) https://www.napoleon.org/en/history-of-the-two-empires/articles/britishstrategic-foreign-policy-1806-1815/ (consultado el 29.08.2019)

James, William. The naval history of Great Britain from the declaration of war by France in 1793, to the accession of George IV, 6 vols. London: Richard Bentley, 1837.

Lipscombe, Nick. Wellington's Eastern Front: The Campaign on the East Coast of Spain 1810-1814. Pen and Sword Military, 2016.

Mackesy, Piers. The War in the Mediterranean, 1803-1810. London: Longmans, Green and Co., 1957.

Mahan, Alfred Thayer. The Influence of Sea Power upon the French Revolution and Empire, 1793-1812, 2 vols. London: Sampson Low, Marston, Searle and Rivington, 1892.

Martin-Lanuza Martínez, Alberto. Diccionario biográfico del generalato español. Reinados de Carlos IV y Fernando VII (1788-1833). Legardeta (Navarra): FEHME, 2012.

Moliner Prada, Antoni. La Catalunya resistent a la dominació francesa (1808-1812). Barcelona: Edicions 62, 1989.

-- La guerrilla en la Guerra de la Independencia. Madrid: Colección Adalid, Ministerio de Defensa, 2004.

-- Tarragona (mayo-junio 1811): una ciudad sitiada durante la Guerra del Francés. Madrid: Consejo Superior de Investigaciones Científicas, Doce Calles, 2011.

Napier, Sir William Francis Patrick. History of the war in the Peninsula, 5 vols. New York: Ams Press, Inc., 1970 (reprinted from the edition of 1862). 
Oman, Sir Charles William Chadwick. A History of the Peninsular War, 7 vols. Oxford: Clarendo,1902-1914.

Quigley, Adam G. Antes morir que rendirse. Testimonios británicos en el asedio de Tarragona, 1811. Tarragona: Associació Setge de Tarragona 1811, 2018.

Ralfe, James. The Naval Biography of Great Britain: Consisting of Historical Memoirs of Those Officers of the British Navy who Distinguished Themselves During the Reign of His Majesty George III, vol. III. Whitmore \& Fenn, 1828.

Ramisa, Maties. "La crisi patriota de 1811 i el radicalisme», Butlletí de la Societat Catalana d'Estudis Històrics, n. XXVIII, 2017, pp. 307-339.

-- Polítics $i$ militars a la Guerra del Francès, 1808-1814. Lleida: Institut d'Estudis Ilerdencs, 2008.

-- «La aplicación de la Constitución de Cádiz en Cataluña (1812-1814), Spagna contemporanea, 2012, n. 41, pp. 7-27.

Saunders, John. Saunders' Portraits and Memoirs of Eminent Living Political Reformers ...: To which is Annexed a Copious Historical Sketch of the Progress of Parliamentary Reform .. J. Dowding, 1840.

Suchet, Louis-Gabriel, duc d'Albufera. Mémoires du Maréchal Suchet, Duc d'Albufera, sur ses campagnes en Espagne, 3 Vols. Paris: Adolphe Bossange; Bossange Père; Firmin Didot, 1828.

Toreno, Conde de. Historia del levantamiento, guerra y revolución de España. Madrid: Atlas, 1953.

Warner, Oliver. The life and letters of Vice-Admiral Lord Collingwood [With portraits, including a self-portrait, and with maps.]. London: Oxford University Press, 1968.

Wikipedia (2019). Wikipedia The Free Encyclopedia, https://en.wikipedia.org/wiki/Edward_Codrington (consultado el 31.08.2019). 